\title{
Diffusion-based model of local Al back surface field formation for industrial passivated emitter and rear cell solar cells
}

\author{
Thomas Lauermann* , Benjamin Fröhlich, Giso Hahn and Barbara Terheiden \\ University of Konstanz, Department of Physics, 78457 Konstanz, Germany
}

\begin{abstract}
In this work, the back surface field (BSF) formation of locally alloyed Al paste contacts employed in recent industrial passivated emitter and rear cell solar cell designs is discussed. A predictive model for resulting local BSF thickness and doping profile is proposed that is based on the time dependent Si distribution in the molten Al paste during the firing step. Diffusion of $\mathrm{Si}$ in liquid $\mathrm{Al}$ away from the contact points is identified as the main differentiator to a full area Al BSF; therefore, a diffusion based solution to the involved differential equation is pursued. Data on the Si distribution in the $\mathrm{Al}$ and the resulting BSF structures are experimentally obtained by firing samples with different metal contact geometries, peak temperature times and pastes as well as by investigating them by means of scanning electron microscopy and energy dispersive $\mathrm{X}$ ray spectroscopy. The $\mathrm{Si}$ diffusivity in the $\mathrm{Al}$ paste is then calculated from these results. It is found that the diffusivity is strongly dependent on the paste composition. Furthermore, the local BSF doping profiles and thicknesses resulting from different contact geometries and paste parameters are calculated from the Si concentration at the contact sites, the diffusivity and solubility data. These profiles are then used in a finite element device simulator to evaluate their performance on solar cell level. With this approach, a beneficial paste composition for any given rear contact geometry can be determined. Two line widths are investigated, and the effects of the different paste properties are discussed in the light of the solar cell results obtained by simulation.
\end{abstract}

\section{KEYWORDS}

silicon; solar cell; PERC; local BSF; screen printing

*Correspondence

Thomas Lauermann, AZUR SPACE Solar Power GmbH, Theresienstr. 2, 74072 Heilbronn, Germany.

E mail: thomas.lauermann@azurspace.com

\section{INTRODUCTION}

In recent years, dielectric rear side passivation has evolved from use on small lab scale solar cells to indus trial solar cells. Although the first are often metalized by evaporated or sputtered $\mathrm{Al}$ in the so called PERC design (passivated emitter and rear cell) [l 13$]$, most of the latter feature contacts established by locally alloying screen printed $\mathrm{Al}$ paste through openings in the passivation layer [4 6]. Because it is desirable to passivate the contacts by a local back surface field (BSF) [7,8], many research have been conducted on the alloying process [9 11] and its application to industrial solar cells $[12,13]$. In the local case, it differs from the homogeneous case as $\mathrm{Si}$ gets transported away from the contact site by gradient driven diffusion, thus forming the well known voids and usually much shallower BSFs. A quantitative understanding of this process is therefore paramount to allow the tailoring of pastes to better suit local contact formation and thereby enhance efficiency in advanced industrial solar cell designs.

Analytical models have been proposed [14] that account for the out diffusion of $\mathrm{Si}$ into the $\mathrm{Al}$ paste within a certain area that is assumed to be fully saturated with $\mathrm{Si}$. The novelty of this work is that it models the actual Si redistri bution process in the paste during firing rather than just an average value and thereby explains the $\mathrm{Si}$ concentration above the contact. It follows approximately a Gaussian shape as measured first by [9]. When the Si concentration over time is known, it can be used to determine not only the BSF thickness but also the resulting doping profile beneath the local contact. This is helpful for the assessment 
of the effective rear side recombination velocity as well as an input parameter into device simulators.

\section{FUNDAMENTALS OF BACK SURFACE FIELD FORIMATION}

The formation of a highly doped $\mathrm{p}^{+}$layer under the rear side $\mathrm{Al}$ metallization of screen printed solar cell is governed by the dissolution of $\mathrm{Si}$ and its subsequent recrystallization during co firing. For the homogeneous case, this process has been extensively studied [15 17]. During the heating ramp, the $\mathrm{Al}$ melts and starts to dissolve more and more $\mathrm{Si}$, as the solubility of $\mathrm{Si}$ in $\mathrm{Al}$ rises with increasing temperature. This can be seen in Figure 1.

At the peak temperature, the paste is saturated with a high content of $\mathrm{Si}$, according to the solubility at that temperature, $c_{0}\left(T_{\text {peak }}\right)$, or $L\left(T_{\text {peak }}\right)$ in Figure 1 . As the temperature falls, so does the solubility, and $\mathrm{Si}$ becomes rejected from the melt until the eutectic concentration of $12.6 \%$ wt is reached. It recrystallizes epitaxially at the $\mathrm{Si} /$ melt interface, incorporat ing a small amount of $\mathrm{Al}$ according to the solid solubility of $\mathrm{Al}$ in $\mathrm{Si}$ at that given temperature $\mathrm{p}^{+}(T)$. This $\mathrm{Al}$, usually in the range of $10^{18}$ to $10^{19} \mathrm{~cm}^{-3}$, acts as $\mathrm{p}$ type dopant forming the high low junction known as BSF. It lowers the surface recombination velocity depending on base resistivity [14] to values around $300 \mathrm{~cm} / \mathrm{s}$ because of its field effect as opposed to the $>10^{6} \mathrm{~cm} / \mathrm{s}$ that can be expected from a pure metal/semiconductor interface of a $\mathrm{p}$ type wafer with a doping density in the range of $10^{16} \mathrm{~cm}^{-3}$.

When using industrial PERC [4] designs by printing a full area $\mathrm{Al}$ electrode on a locally opened dielectric passiv ation layer, it is still beneficial to passivate the remaining contact sites as introduced by [7] and discussed in [8]. In the local case, however, BSF formation becomes compli cated by lateral diffusion as illustrated in Figure 2. The strong lateral concentration gradient drives $\mathrm{Si}$ away from the contact sites $[9,10,13,14,18]$. This lower concentration

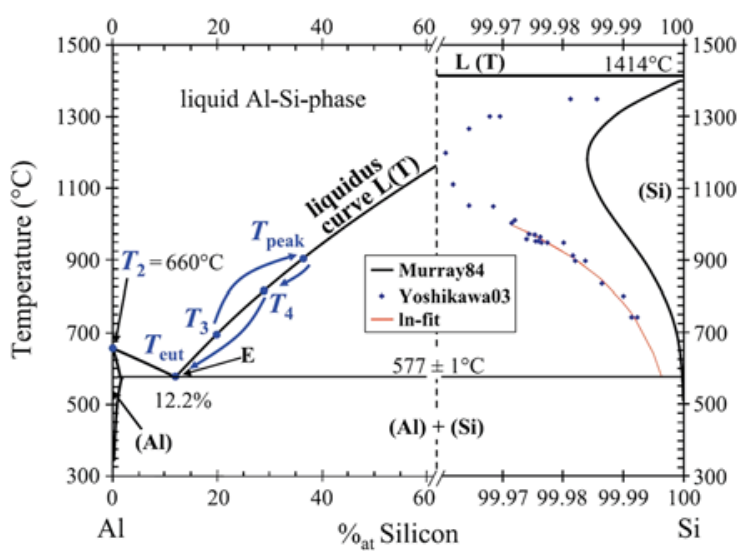

Figure 1. Al Si phase diagram with the temperature depen dence of liquid and solid solubilities taken from [11] with solid solubility data from [19] and [20]

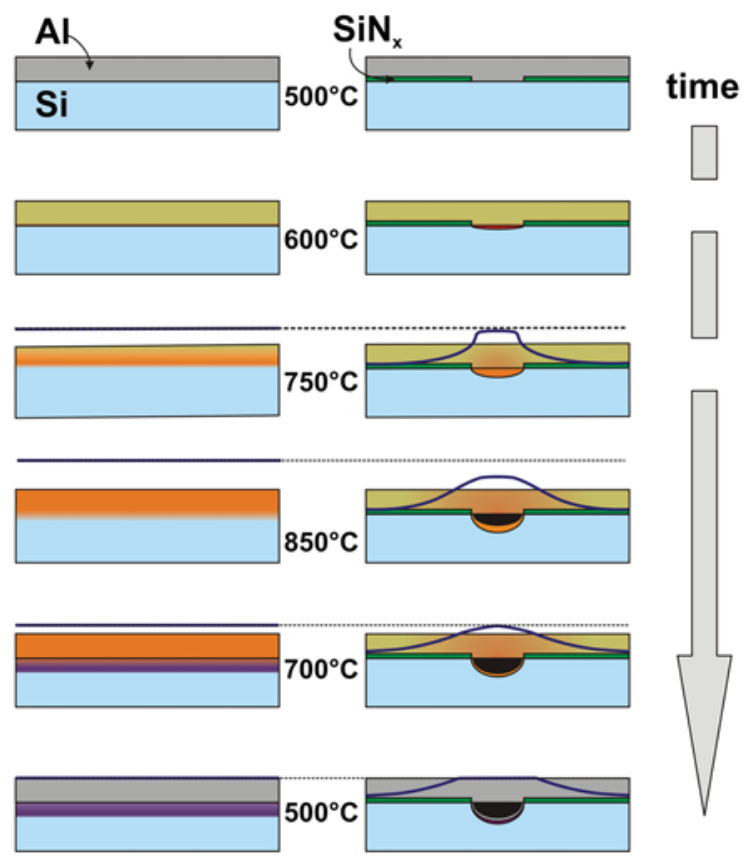

Figure 2. Homogeneous BSF formation compared with local BSF formation as described in [13]. The curve represents local Si content in the paste, and the dashed line represents the temperature dependent Si solubility according to [19].

of $\mathrm{Si}$ available during the cooling ramp results in void formation and a shallow or nonexistent BSF.

Because BSF recrystallization can only occur with $\mathrm{Si}$ concentrations exceeding the solubility of $\mathrm{Si}$ in the melt, the BSF formation starts later during the cooling ramp, resulting in shallower BSFs and a lower doping. Both effects deteriorate the passivation ability of the BSF, and in the extreme case, if the concentration is below the eutectic concentration at the start of the cool down phase, no BSF is formed at all. This is observed when the contacts are too narrow and only small quantities of Si are available to be dissolved in the paste or the Si diffuses too far away from the contacts.

\section{ANALYTICAL DESCRIPTION OF THE DIFFUSION PROBLEM}

The local concentration of $\mathrm{Si}$ dissolved in the $\mathrm{Al}$ paste at position $x$ and time $t$ is

$$
c_{\mathrm{Si}}(t, x)=\frac{m_{\mathrm{Si}, \mathrm{dis}}(t, x)}{m_{\mathrm{Al}}+m_{\mathrm{Si}, \mathrm{dis}}(t, x)}
$$

and its concentration is given in $\%_{\mathrm{wt}}$ unless noted other wise. We assume that the total amount of $\mathrm{Al}$ is homoge neously distributed over the area and constant over time. This is valid, because the amount of $\mathrm{Al}$ incorporated into the BSF is in the range of $0.01 \%$ and can be neglected. 
Because the diffusivity scales with temperature according to the Arrhenius law, we can assume that the most significant part of the diffusion process takes place during the peak firing temperature. Diffusion processes at temperatures more than $20^{\circ} \mathrm{C}$ below $T_{\text {peak }}$ therefore have only a minor impact on the Si redistribution because of their lower diffusivity. Geometrical variations such as the deepening of the contact crater are also not taken into account for their small influ ence. For simplicity, we split the problem into three tempo rally separated phases, illustrated in Figure 3:

(I) The heat up, where the paste above the contact region saturates locally with $\mathrm{Si}$ until it reaches $c_{0}$ $\left(T_{\text {peak }}\right)$

(II) The peak plateau at $T_{\text {peak }}$ where the diffusion takes place

(III) The cool down, where BSF epitaxy takes place

At the end of phase I, all the dissolved $\mathrm{Si}$ is assumed to be above the line shaped contact with the width $2 w$. We state as initial conditions that $c_{\mathrm{Si}}(0, x)$ is $c_{0}\left(T_{\text {peak }}\right)$ at the beginning of phase II $(t=0)$ above the contact site $(w<x<w)$, and zero elsewhere. Mathematically, this is expressed as a sum of Heaviside step functions as the initial conditions:

$$
c_{\mathrm{Si}}(0, x)=c_{0}\left(T_{\text {peak }}\right) \cdot[\Theta(x+w) \quad \Theta(x \quad w)]
$$

If we then assume that the concentration is uniform over the height of the paste (typical Al thickness: $2030 \mu \mathrm{m}$ ), we have to solve the diffusion equation in one dimension:

$$
\frac{\partial}{\partial t} c_{\mathrm{Si}}(t, x)=D \cdot \frac{\partial^{2}}{\partial x^{2}} c_{\mathrm{Si}}(t, x)
$$

For this partial differential equation, there exists a fundamen tal solution of the form

$$
G(t, x)=\frac{1}{\sqrt{ } 4 \pi D t} \cdot \exp \left(\frac{x^{2}}{4 D t}\right)
$$

when using a delta function as initial condition. This is the well known Gaussian distribution, and to obtain the solution to our special initial condition, we utilize it as a Green's function and convolute with the initial condition $c_{\mathrm{Si}}(0, x)$ :

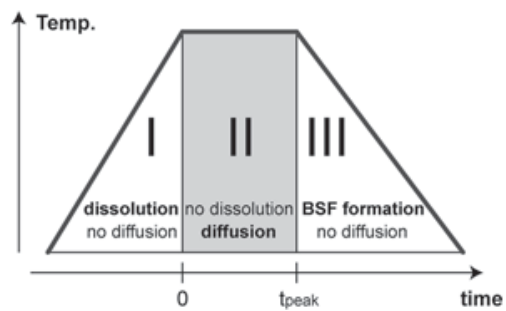

Figure 3. Simple firing model with heating, dwell time, and cool down phase. Diffusion is only considered in phase II between

$$
t=0 \text { and } t=t_{\text {peak }} \text {. }
$$

$$
\begin{aligned}
& c_{\mathrm{Si}}(t, x)=\int_{-\infty}^{\infty} G(t, x \quad y) \cdot c(0, y) d y \\
& =\frac{c_{0}\left(T_{\text {peak }}\right)}{\sqrt{ } 4 \pi D t} \int_{-\infty}^{\infty} \exp \left(\frac{(x y)^{2}}{4 D t}\right) \\
& \cdot[\Theta(y+w) \quad \Theta(y \quad w)] d y
\end{aligned}
$$

Integration over the step function yields us a sum of error functions, which resembles the desired concentration of $\mathrm{Si}$ in the $\mathrm{Al}$ paste at the time $t$ at the end of phase II.

$$
c_{\mathrm{Si}}(t, x)=\frac{1}{2} c_{0}\left(T_{\text {peak }}\right) \cdot\left[\operatorname{erf}\left(\frac{x+w}{\sqrt{ } 4 D t}\right) \quad \operatorname{erf}\left(\frac{x}{\sqrt{ } 4 D t}\right)\right]
$$

This equation fulfills the mass conservation law for the sili con dissolved in the paste, because

$$
\int_{-\infty}^{\infty}\left[\operatorname{erf}\left(\frac{x+w}{\sqrt{ } 4 D t}\right) \quad \operatorname{erf}\left(\frac{x}{\sqrt{ } 4 D t}\right)\right] d x=4 w
$$

holds for any given $t$. The length scale of interest is the denominator $\sigma=\sqrt{ } 4 D t$. It is closely related to the Si spread mentioned in former publications and can be measured to calculate the diffusivity $D$ of the paste at a given temperature $T_{\text {peak }}$ when the peak dwell time $t_{\text {peak }}$ is known.

Equation (6) is illustrated in Figure 4. It can be seen that when $\sigma$ reaches the dimension of the line opening, $c_{\mathrm{Si}}\left(t_{\text {peak }}, x\right)$ above the contact barely exceeds the eutectic composition $c_{\text {eut }}=12.6 \%$, indicated in Figure 4 as dashed line, so only minimal BSF formation can be expected during phase III.

The maximum BSF thickness is calculated after [21] by considering the concentration $c_{\mathrm{Si}}$ in the alloy of height $h$ above the eutectic concentration $c_{\text {eut }}$ :

$$
d_{\mathrm{BSF}}=\frac{\rho_{\text {alloy }}}{\rho_{\mathrm{Si}}} \cdot\left(\frac{c_{\mathrm{Si}}\left(t_{\text {peak }}, 0\right)}{1 \quad c_{\mathrm{Si}}\left(t_{\text {peak }}, 0\right)} \quad \frac{c_{\text {eut }}}{1 \quad c_{\text {eut }}}\right) \cdot h
$$

Here, $\rho_{\text {alloy }}$ and $\rho_{\mathrm{Si}}$ are the respective mass densities. How ever, this relation can also be used to estimate the $\mathrm{Si}$

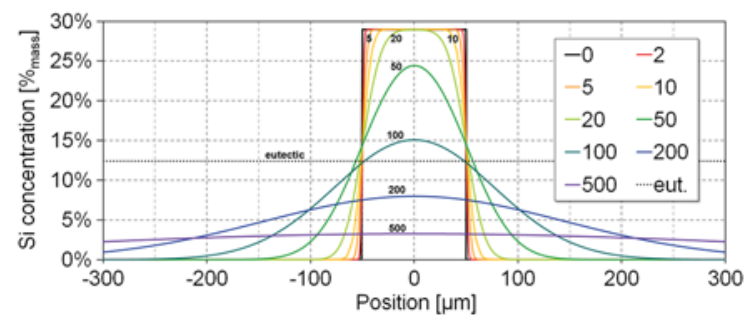

Figure 4. Evolution of Si distribution in the paste at various stages of diffusion. Resulting from a $100 \mu \mathrm{m}$ wide contact fired at $800^{\circ} \mathrm{C}$ ( $c=29 \%$ ). The unit of the color coding, also given at the respective lines, is the time dependent spread $\sigma$ given in $\mu \mathrm{m}$. 
concentration at the end of phase II when the thickness of the resulting BSF is known.

\section{APPLICATION TO REAL-WORLD CONDITIONS}

To account for the fact that a strict separation of dissolution and diffusion is impossible during a realistic firing step, the influence of the obvious deviations from the assumed phase I II III model has to be assessed.

- Diffusion occurs not only strictly during phase II but to a lesser extent already during lower temperatures in phase I, so the concentration at $t=0$ is no sharp step function but already somewhat softened. This can be accounted for by assuming a nonzero diffusion prod uct $\sqrt{ } D t$ at the start of phase II as is suggested by Figure 5.

- During phase II, additional Si becomes dissolved as the concentration falls locally because of diffusion. This can be seen in particular at the edges of the formed voids where deeper structures than the plateau level are formed as described by other authors [22]. It is related to the edge part being affected first by the out diffusion that drives the additional solution, while the region in the center of the contact has a higher $\mathrm{Si}$ concentration in the paste during the peak time.

Although it is straightforward to shift the time scale by a fixed fraction of the heat up time, the second effect is harder to quantify. It can be understood as the addition of $\mathrm{Si}$ into the melt during phase II. This amount is dissolved at the edges, leading to the regularly observed deviation from the elliptic form of the voids as visualized in Figure 6. The additional amount of $\mathrm{Si}$ is proportional to the bulge size. Because it increases concentration near the edges, it effectively resembles a broadening of the contact width, scaling linearly with the time at peak temperature.

To account for these deviations, it is helpful to compare sets of contacts that differ both in peak time as well as width. It then can be seen that when extrapolating toward $t=0$, the spread value $\sigma$ is always above zero. The same

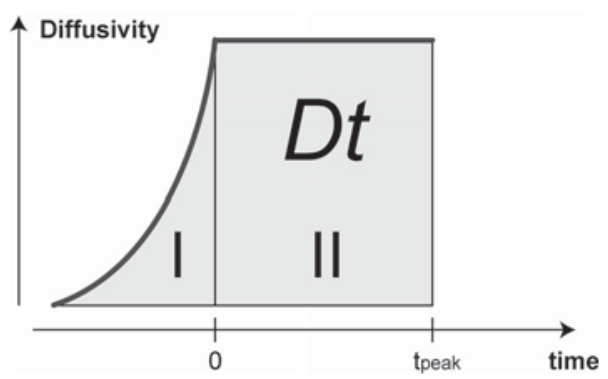

Figure 5. As diffusivity rises exponentially with temperature, it contributes to $\sqrt{ } D t$ before phase II. Therefore, an offset in time is introduced, corresponding to the area underneath the exponen tial curve. This offset scales with heat up time.

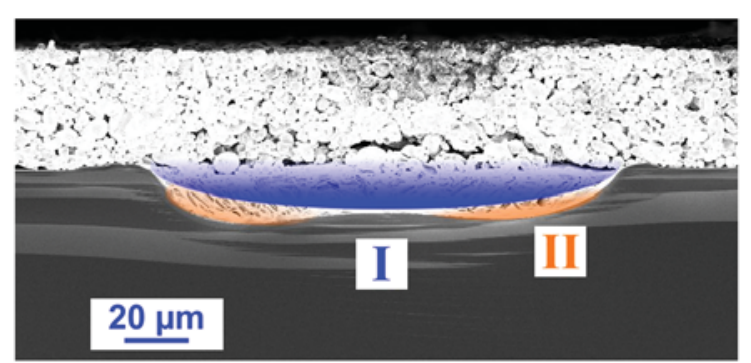

Figure 6. Scanning electron microscopy cross section of a contact line with "bulges" at the edge. The amount of $\mathrm{Si}$ dissolved during phase I is highlighted in blue (dark), additional dissolution during phase II in orange (bright). The shapes are just a guide to the eye.

holds for the line width $2 w$ approaching zero. It is observed that $\sigma$ converges against a finite width for a given peak time $t$. This is referred to as "width correction" in the ex perimental part and scales roughly linear with $t$, which jus tifies the assumption that the Si dissolution in phase II is governed by a finite dissolution velocity that is constant for a given paste.

Another effect is found in real pastes as opposed to model conditions. The paste can already contain some $\mathrm{Si}$, which was intentionally added by the paste manufacturer to provide more $\mathrm{Si}$ during BSF formation as suggested by [10]. This results in the distribution function not falling to zero at large distances but reaching a plateau. It is math ematically accounted for shifting the abscissa of eq. (6) by the added Si base content.

\section{EXPERIMENTAL DETERMINATION OF DIFFUSIVITY}

Test samples with local contacts are manufactured from $125 \mathrm{~mm} \mathrm{Cz}$ Si wafers with $180 \mu \mathrm{m}$ thickness and a base resistivity of $2 \Omega \mathrm{cm} . \operatorname{SiN}_{x}(80 \mathrm{~nm})$ is deposited in a plasma enhanced chemical vapor deposition reactor and is subsequently structured by picosecond laser ablation. Each wafer receives the same pattern consisting of free standing lines of various widths ranging from 60 to $150 \mu \mathrm{m}$. In this context, freestanding means that the dis tance between individual lines is substantially larger than $\sigma$ and neighboring contacts do not influence each other. These wafers are divided into three groups, being screen printed with three commercially available $\mathrm{Al}$ pastes from different manufacturers. Each group is then divided into four subgroups, which are fired at the same wafer peak temperature $T_{\text {peak }}$ of $840^{\circ} \mathrm{C}$ but with different belt speeds of $2,4,6$, and $7 \mathrm{~m} / \mathrm{min}$ to achieve different peak tempera ture times of $1.7,2,3$, and $6 \mathrm{~s}$ within the temperature range of $T_{\text {peak }} \quad 20^{\circ} \mathrm{C}<T<T_{\text {peak }}$. Note that to achieve a given wafer temperature, the setpoint of the furnace is chosen above $840^{\circ} \mathrm{C}$ for the faster belt speeds. The longer peak times were selected to obtain a reasonable data range for 
analysis. The firing processes used in the industry usually feature peak zone times below $2 \mathrm{~s}$ for throughput reasons.

The width of the Si diffusion in the paste, visible by the darker appearance of the paste due to lamella formation during recrystallization [16], is measured by optical mi croscopy on the paste surface. Because the solid solubility of $\mathrm{Si}$ in $\mathrm{Al}$ below $577{ }^{\circ} \mathrm{C}$ is $1.4 \%_{\mathrm{wt}}$ [19], it is used as fixed point in the Si spread evaluation. Afterward, the wafers are cleaved into $1 \mathrm{~cm}^{2}$ scanning electron microscopy samples for determination of BSF thickness in the cross sectional view. The Si distribution in the paste is determined by means of energy dispersive $\mathrm{X}$ ray spectroscopy (EDX). The cross section of the paste near the contact sites is mapped for a $3 \mathrm{~h}$ integration time each, and the ratio between $\mathrm{Si}$ and $\mathrm{Al}$ signals is determined for each $x$ position to obtain the position dependent $\mathrm{Si}$ concentration in the paste. The results of the three respective pastes can be seen in Figure 7(a) (c) together with a view of the measurement area, taken from the $60 \mu \mathrm{m}$ lines in the $2 \mathrm{~s}$ firing group.

The value of $\sigma$ can now be obtained in two ways, first by fitting the model to the measured $\mathrm{Si}$ spread data, which is available for a variety of line widths and firing times. The other method is directly comparing a plot of the obtained error functions to a measured EDX profile. The results and the obtained values for the diffusivity and the Si base level are given in Table I for the different firing times and pastes. The effect of additional Si dissolution by the paste during phase 2 is also taken into account by introducing a width correction, which is a measure for the additional Si taking part in the diffusion process. It is worth noting that this width correction scales roughly linear with time; therefore, a paste dependent Si dissolution velocity can be assumed.

Different strategies for paste optimization become apparent from the results: Paste A shows almost no $\mathrm{Si}$ addition but a high diffusivity combined with strong $\mathrm{Si}$ dissolution from the contact sites to achieve a wide satura tion of the paste with Si. This can be beneficial in cell designs where the contact pitch is small and the metallization fraction is comparably high, so neighboring contacts can benefit from the $\mathrm{Si}$ in their vicinity. In contrast, the diffusivity of paste B is reduced to one third compared with paste A with considerably lower Si dissolution, visible in shallower voids. The origin of this reduced diffusivity is unknown to the authors because it is a trade secret of the paste manufacturer. One could argue, however, that smaller par ticles with less interconnections inhibit the interparticle transport. This paste is suited to keep the Si saturation constricted to the contact area. This is useful when the rear contacts have a pitch in the $1 \mathrm{~mm}$ range and are unable to influence the $\mathrm{Si}$ distribution of each other. Si is added sparsely to the paste, as can be seen in the form of a Si rich chunk at position 50 in Figure 7(b). Paste $\mathrm{C}$ is between pastes $\mathrm{A}$ and $\mathrm{B}$ regarding diffusivity and dissolution rate but is able to enhance the $\mathrm{Si}$ saturation by its elevated amount of $\mathrm{Si}$ of around $4 \%$ intentionally added homogeneously to the paste by the manufacturer. This value was also obtained by EDX on dried and fired samples.
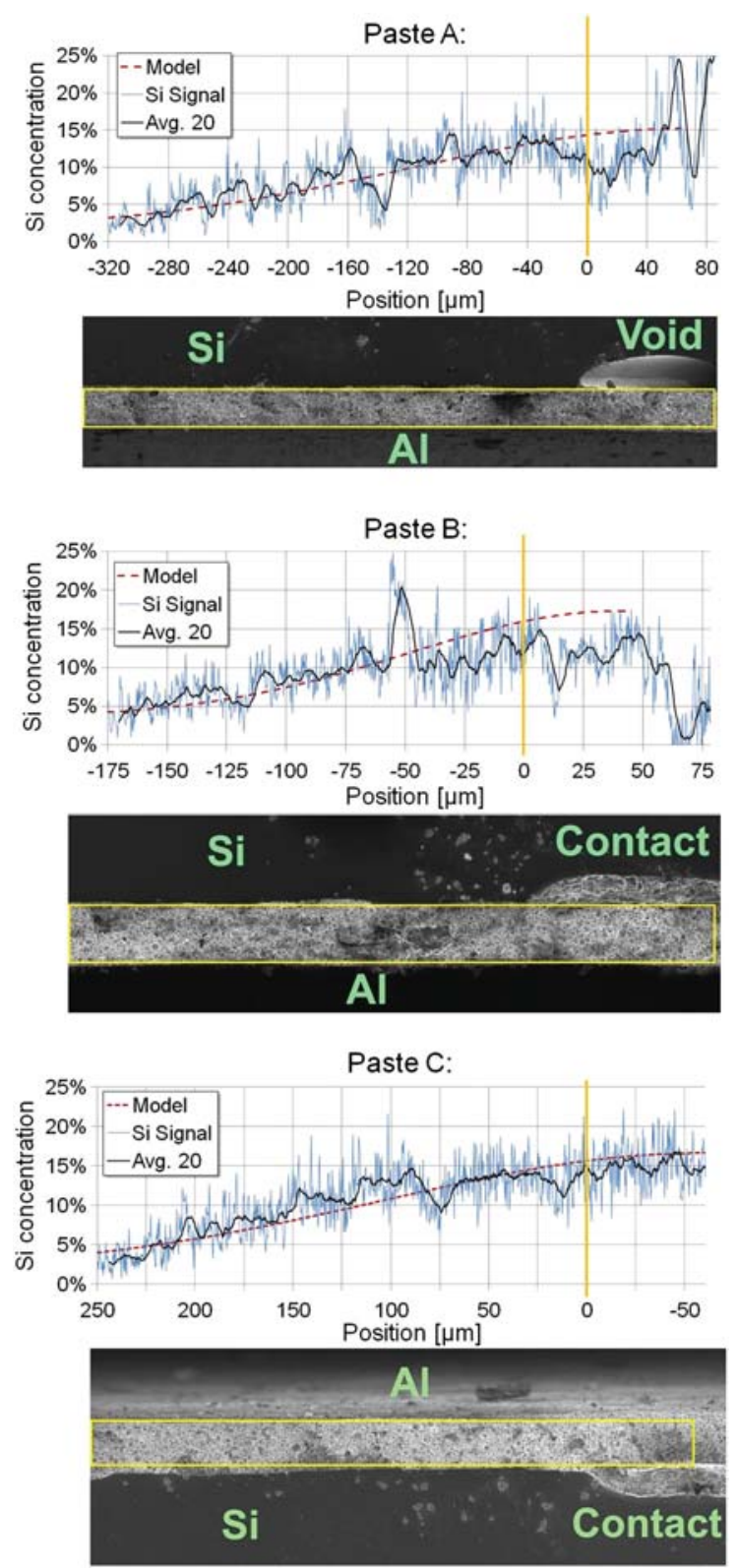

Figure 7. Energy dispersive $X$ ray spectroscopy measurements of the Si distribution in the paste and a scanning electron micros copy cross section of the area of interest. A cross section of the paste was scanned (box), and the resulting signals for each position (Si signal) and averaged over 20 positions (Avg. 20) are shown. Additionally, the Si concentration modeled by eq.

(6) is also shown in dashed lines for comparison.

\section{CALCULATION OF RESULTING DOPING PROFILE}

To obtain the doping profile over $d_{\mathrm{BSF}}$, the temperature dependent solubilities of $\mathrm{Al}$ in $\mathrm{Si}$ have to be taken into account. BSF epitaxy starts at $t_{\text {epi }}$ when the $\mathrm{Si}$ concentration above the contact $c_{\mathrm{Si}}\left(t_{\mathrm{epi}}, 0\right)$ exceeds the 
Table I. Results of the scanning electron microscopy experiment: spread, width correction, base content of Si without dissolution, and diffusivity for each paste.

\begin{tabular}{|c|c|c|c|c|c|}
\hline Paste & $t_{\text {peak }}[\mathrm{s}]$ & $\sigma[\mu \mathrm{m}]$ & $\begin{array}{c}w \text { corr. } \\
{[\mu \mathrm{m}]}\end{array}$ & $\begin{array}{c}\text { Sibase } \\
{[\%]}\end{array}$ & $\begin{array}{c}D \\
{\left[\mu \mathrm{m}^{2} / \mathrm{s}\right]}\end{array}$ \\
\hline \multirow[t]{4}{*}{$A$} & 1.7 & 185 & +80 & 2 & 5000 \\
\hline & 2 & 201 & +100 & & \\
\hline & 3 & 246 & +140 & \pm 2 & \pm 250 \\
\hline & 6 & 348 & +260 & & \\
\hline \multirow[t]{4}{*}{ B } & 1.7 & 110 & 0 & 4 & 1800 \\
\hline & 2 & 120 & +10 & & \\
\hline & 3 & 146 & +20 & \pm 2 & \pm 100 \\
\hline & 6 & 207 & +60 & & \\
\hline \multirow[t]{4}{*}{ C } & 1.7 & 140 & +20 & 4 & 3000 \\
\hline & 2 & 152 & +30 & & \\
\hline & 3 & 186 & +50 & \pm 2 & \pm 150 \\
\hline & 6 & 263 & +120 & & \\
\hline
\end{tabular}

maximum solubility at the current temperature $T_{\text {epi }}=T$ $\left(t_{\text {epi }}\right)$, which is when

$$
c_{\mathrm{Si}}\left(t_{\text {epi }}, 0\right)=c_{0}\left(T_{\text {epi }}\right)
$$

which occurs in the local case usually well after $t_{\text {peak }}$. The resulting BSF profile can then be calculated from the solubility data if we discretize the epitaxy process into temperature steps from $T_{\text {epi }}$ down to $T=577^{\circ} \mathrm{C}$. During each temperature step, $\mathrm{d} T$ recrystallizes a small amount of $\mathrm{Si}$ because of the difference between old and new solubility, forming a layer of thickness $\mathrm{d} z$, with the temperature dependent amount of $\mathrm{Al}$ doping $\mathrm{p}^{+}(T)$.

$$
\mathrm{d} z\left(\mathrm{p}^{+}\right)=h_{\text {alloy }}(T) \cdot\left(c_{0}(T) \quad c_{0}(T+\mathrm{d} T)\right)
$$

This layer for layer principle is illustrated in Figure 8. Note that as more and more melt recrystallizes with falling temperature, the height of the melt in the $z$ direc tion $h(T)$ diminishes proportionally with its Si depletion. An integration to obtain $z\left(\mathrm{p}^{+}\right)$can be performed by a spreadsheet calculator, when the liquid solubility data of $\mathrm{Si}$ in $\mathrm{Al} c_{0}(T)$ and the solid solubility data of $\mathrm{Al}$ in $\mathrm{Si} \mathrm{p}^{+}(T)$ is present in the form of tables or diagrams, for example, by [19]. An analytical approximation with

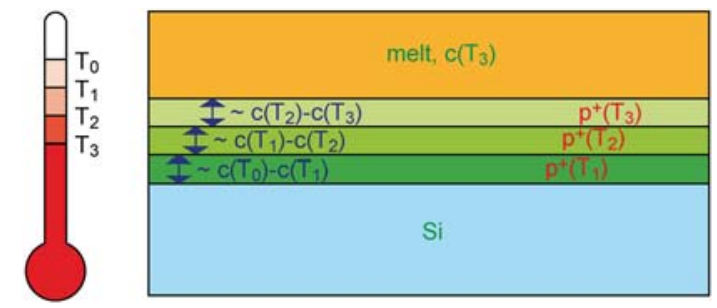

Figure 8. Discretization of the BSF formation process. At every step $\mathrm{d} T$, the thickness increases depending on $\mathrm{d} T$, and a doping dependent on $T$ is incorporated. the ln function can be used in the temperature range of interest as well [11]. The inverse function of $z\left(\mathrm{p}^{+}\right)$is the desired doping profile $\mathrm{p}^{+}(z)$.

As an example, the resulting profiles from three kinds of freestanding contacts are calculated, one being $60 \mu \mathrm{m}$ wide, the second being $100 \mu \mathrm{m}$ wide, and the third being $120 \mu \mathrm{m}$ wide. They are calculated under the assumptions $t_{\text {peak }}=2 \mathrm{~s}, T_{\text {peak }}=840^{\circ} \mathrm{C}$, so that $c_{0}\left(T_{\text {peak }}\right)=33 \%$. The pure $\mathrm{Al}$ height is set to $20 \mu \mathrm{m}$, accounting for the lower $\mathrm{Al}$ mass of the pastes' porous structure compared with a solid Al layer. All three pastes are considered, as well as a hypo thetical paste $\mathrm{D}$, which consists of the diffusive properties of B combined with a Si content of $9 \%$. The Si concentra tion directly above the contacts is averaged and given in Table II as well as the resulting BSF thicknesses according to eq. (8). The resulting profiles for paste $\mathrm{D}$ are shown in Figure 9. Please note that actual BSF profiles show higher electrically active dopant concentrations in measured elec trochemical capacitance voltage profiles, because modern

Table II. Average Si concentration above contact sites contributing to BSF formation and the resulting BSF thickness as calculated by the presented model.

\begin{tabular}{lccc}
\hline Paste & $\begin{array}{c}\text { Line } \\
\text { width }[\mu \mathrm{m}]\end{array}$ & $\begin{array}{c}\text { Si } \\
\text { conc.[\%] }\end{array}$ & $\begin{array}{c}\text { BSF } \\
\text { thickness [ } \mu \mathrm{m}]\end{array}$ \\
\hline \multirow{4}{*}{ B } & 60 & 15.1 & 0.73 \\
& 100 & 17.6 & 1.44 \\
& 120 & 18.5 & 1.71 \\
60 & 13.3 & 0.24 \\
C & 100 & 17.5 & 1.41 \\
& 120 & 19.2 & 1.92 \\
& 60 & 13.2 & 0.21 \\
D & 100 & 18.0 & 1.56 \\
& 120 & 19.4 & 1.98 \\
& 60 & 17.5 & 1.41 \\
Full BSF from homogeneous alloying & 33.0 & 7.02 \\
\hline
\end{tabular}

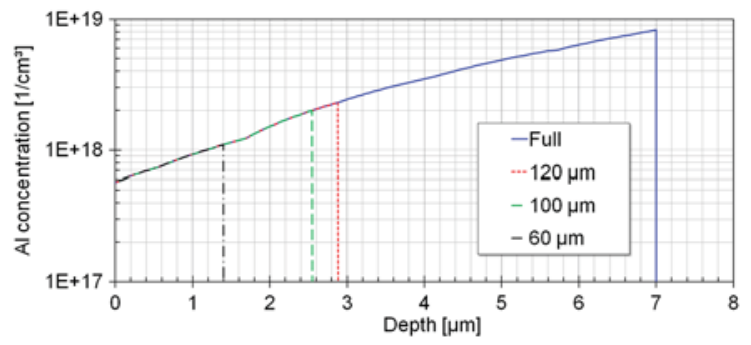

Figure 9. Exemplary calculated Al profiles resulting from the spreadsheet integration of paste $D$, using Yoshikawa's solubility data [20]. The $7 \mu \mathrm{m}$ deep profile is expected from the full BSF epitaxy at homogeneously contacted rear sides. All partial pro files from the different line widths can be derived by cutting off the profile at the desired depth. 
pastes contain additional $\mathrm{p}$ type dopants such as boron $[23,24]$. It is also conceivable that they could contain alloying agents that alter the maximum solid state solubil ity of $\mathrm{Al}$ in epitaxially grown $\mathrm{Si}$ in a ternary material system [25].

\section{LOCAL BSF PERFORMANCE ON SOLAR CELL LEVEL}

The obtained $\mathrm{Al}$ doping profiles are used as input in Sentaurus [26], a finite element device simulator, together with the pure PERC case, that is, no $\mathrm{p}^{+}$passivation under the contacts, as reference. The simulation is set up as a 2D unit cell of $180 \mu \mathrm{m}$ thickness around one front grid finger according to [27] with a $2.4 \mathrm{~mm}$ front grid spacing and two rear contacts, spaced $1.2 \mathrm{~mm}$ apart. Because the problem is symmetric, the length of the unit cell is reduced to the half pitch of $1.2 \mathrm{~mm}$ for simplicity. Two solar cell rear designs are chosen, the first one being $60 \mu \mathrm{m}$ wide lines, the second being $120 \mu \mathrm{m}$ wide lines. Note that the contact resistance halves with the wider contacts, which has a slight effect on the fill factor between the two groups. The BSF doping profile calculated from the data in Table II for each paste and line width is applied above each contact area, assuming that every acceptor atom contributes to the net doping of the BSF. The cases of no BSF passivation and the case of the full $3.5 \mu \mathrm{m}$ BSF profile expected from homogeneous BSF formation are also considered as lower and upper boundaries. Further data entering the simulation is a measured $\mathrm{POCl}_{3}$ emitter profile resulting in a sheet re sistance of $53 \Omega /$ sq. passivated with fired plasma enhanced chemical vapor deposition $\operatorname{SiN}_{x}$, a Shockley Read Hall lifetime of $400 \mu$ s for the bulk material (no light induced degradation is considered here) and a defect density corre sponding to $100 \mathrm{~cm} / \mathrm{s}$ combined with a fixed charge density of $6 \times 10^{12} \mathrm{~cm}^{-2}$ for the dielectrically passivated regions of the rear side. The optical generation across the bulk is calculated from ray tracing, assuming a random pyramid front texture. The results of the simulation assuming a base resistivity of $2 \Omega \mathrm{cm}$ and a front grid finger width of $80 \mu \mathrm{m}$ can be seen in Table III. A diagram plotting the efficiencies is given in Figure 10.

The effect of the contact passivation on solar cell efficiency can be seen for different BSF thicknesses. In the unpassivated case, the cell voltage is clearly limited by recombination of the contacts, showing $0.2 \%$ lower efficiency for the $120 \mu \mathrm{m}$ lines than for the $60 \mu \mathrm{m}$ lines. In the fully passivated case, there is only a very subtle effect of contact width. This trend reverses when regarding all investigated pastes, the loss by increasing contact width is clearly offset by the gain in BSF thickness and, there fore, better contact passivation. Although pastes A, B, and $\mathrm{C}$ perform on a roughly equal level on $120 \mu \mathrm{m}$ contact widths, paste A shows the best performance with $60 \mu \mathrm{m}$ line widths. The hypothetical paste $\mathrm{D}$, however, that merges all beneficial properties of the investigated pastes performs better than the other pastes under all conditions,
Table III. Simulated solar cell results for cells with local BSFs resulting from different pastes.

\begin{tabular}{lrrrrr}
\hline Paste & $\begin{array}{c}\text { Line width } \\
{[\mu \mathrm{m}]}\end{array}$ & $\begin{array}{c}j_{\mathrm{SC}}[\mathrm{mA} / \\
\left.\mathrm{Cm}^{2}\right]\end{array}$ & $\begin{array}{c}V_{\mathrm{OC}} \\
{[\mathrm{mV}]}\end{array}$ & $\begin{array}{c}\text { Efficiency } \\
{[\%]}\end{array}$ & $\begin{array}{c}\mathrm{FF} \\
{[\%]}\end{array}$ \\
\hline No LBSF & 60 & 38.2 & 628 & 18.9 & 78.8 \\
& 120 & 38.0 & 623 & 18.7 & 79.1 \\
$\mathrm{~A}$ & 60 & 38.7 & 646 & 19.8 & 79.1 \\
& 120 & 38.7 & 648 & 20.0 & 79.4 \\
B or C & 60 & 38.5 & 638 & 19.4 & 79.0 \\
& 120 & 38.8 & 650 & 20.0 & 79.4 \\
D & 60 & 38.8 & 654 & 20.1 & 79.1 \\
& 120 & 38.8 & 655 & 20.2 & 79.4 \\
Homog. & 60 & 38.9 & 663 & 20.4 & 79.0 \\
profile & 120 & 38.9 & 659 & 20.4 & 79.4 \\
\hline
\end{tabular}

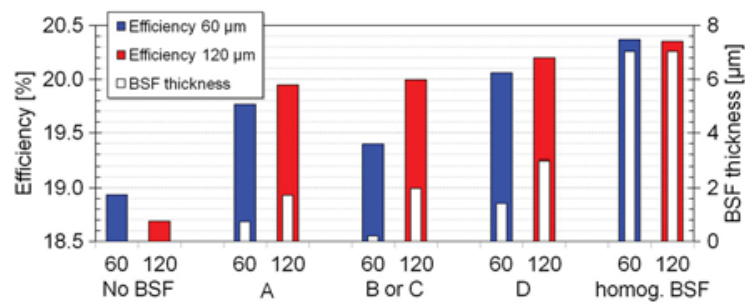

Figure 10. Effect of different BSF profiles on solar cell level as simulated with 60 and $120 \mu \mathrm{m}$ wide rear contact designs using pastes A D. The thickness of the profiles used is also provided in white.

showing a $0.3 \%$ absolute efficiency gain for the $60 \mu \mathrm{m}$ design and a $0.2 \%$ absolute efficiency gain for the $120 \mu \mathrm{m}$ design. It is thereby possible to increase solar cell perfor mance with proper paste engineering suitable to accommo date the special requirements of a locally contacted solar cell design, as was shown by Rauer et al. [10].

Experimental data from real solar cells for comparison can, for example, be found in [8] or in [13]. Empirically, it has been found that the difference between a shallow and a thick BSF accounts for an efficiency gain of $0.3 \%$ abs.

\section{SUMMARY}

In this paper, insight in the process of local BSF formation beneath the rear contacts of industrial PERC solar cells was provided. An analytical model was presented that is based on solving the diffusion equation for the Si dissolved by the molten $\mathrm{Al}$ paste during contact firing. Because the concentration of $\mathrm{Si}$ in the $\mathrm{Al}$ follows a bell shaped curve as measured by previous authors, this approach is considered to be more general than earlier publications on this topic, assuming a spatially constant dilution of $\mathrm{Si}$ in the paste.

It was found that the Si distribution can be described as a sum of error functions depending on the line width and paste parameters such as diffusivity and dissolution velocity of additional Si during the peak firing phase. This 
distribution was verified by EDX investigation of different $\mathrm{Al}$ pastes after firing, and the diffusivity of each paste was derived by optical measurement of the Si spread of differ ent line widths subjected to a variety of peak times.

The investigated pastes differ in three main parameters that affect BSF formation beneficially: Paste A benefits from its rapid Si dissolution ability caused by its high diffusion constant, paste B has a significantly reduced diffusion constant, keeping the Si close to the contact site, and paste $\mathrm{C}$ supplies a significant amount of additional $\mathrm{Si}$ in the paste to achieve a higher Si saturation at any given point.

With this information, the local BSF doping profiles and thicknesses resulting from different contact geometries and paste parameters could be calculated from the Si concentra tion at the contact sites during the cool down ramp, using a spreadsheet calculator and solid state solubility data from literature. These profiles are then used in Sentaurus device to evaluate the performance of $\mathrm{Al}$ pastes in a PERC design on solar cell level. The simulation results highlight the importance of contact passivation for solar cells efficiency, leading to the result that within all investigated pastes $120 \mu \mathrm{m}$ wide lines are preferred to $60 \mu \mathrm{m}$ lines because the passivation effect of the thicker BSFs outweighs the larger contact area. It also suggests that a hypothetical paste $\mathrm{D}$ with the diffusive properties of paste $\mathrm{B}$ but an additional Si content of $9 \%$ leads to an efficiency gain of $0.20 .3 \%$ absolute compared with the best investigated real paste. There fore, this contribution concludes that paste improvement leading to higher solar cell efficiencies on locally contacted solar cell designs is achievable by adapting the pastes to the requirements of local BSF formation.

\section{ACKNOWLEDGEMENTS}

The authors would like to extend their gratitude to J. Engelhardt, L. Mahlstaedt, S. Ohl, B. Rettenmaier, J. Ruck, F. Mutter, and C. Gründler for their support during process ing, A. Zuschlag, S. Öner, and A. Hammud for the electron microscopy as well as P. Altermatt for the support with the simulation. The financial support for parts of this work by the German BMU under contract FKZ 325168 and 0325079 is gratefully acknowledged.

\section{REFERENCES}

1. Blakers AW, Wang A, Milne AM, Zhao J, Green MA. 22.8\% efficient silicon solar cell. Applied Physics Letters 1989; 55: 1363 1365, DOI: 10.1063/1.101596

2. Glunz SW, Knobloch J, Hebling C, Wettling W. The range of high efficiency silicon solar cells fabricated at Fraunhofer ISE. Proceedings 26th IEEE PVSC 1997; 231 234, DOI: 10.1109/PVSC.1997.654071

3. Schneiderlöchner E, Preu R, Lüdemann R, Glunz SW. Laser fired rear contacts for crystalline silicon solar cells. Progress Photovoltaics Research and Applica tions 2002; 10: 29 34, DOI: 10.1002/pip.422

4. Agostinelli G, Choulat P, Dekkers HFW, De Wolf S, Beaucarne G. Screen printed large area crystalline silicon solar cells on thin substrates. Proceedings 20th EU PVSEC 2005; 13391342.

5. Gautero L, Rentsch J, Weiss L, Kohn N, Eigner S, Zimmer M, Specht J, Nekarda J, Stüwe D, Retzlaff M, Biro D, Sallese J M, Preu R. Industrial approach for the deposition, through vias wet opening and firing activation of a backside passivation layer applied on solar cells. Proceedings 23th EU PVSEC 2008; 1453 1457, DOI: 10.4229/23rdEUPVSEC2008 2CV.4.38

6. Gatz S, Hannebauer H, Hesse R, Werner F, Schmidt A, Dullweber T, Schmidt J, Bothe K, Brendel R. $19.4 \%$ efficient large area fully screen printed silicon solar cells. Physica Status Solidi RRL 2011; 5(4): 147 149, DOI: 10.1002/pssr.201105045

7. Wang A, Zhao J, Green MA. 24\% efficient silicon solar cells. Applied Physics Letters 1990; 57(6): 602 604, DOI: 10.1063/1.103610

8. Lauermann T, Lüder T, Scholz S, Hahn G, Terheiden B. Enabling dielectric rear side passivation for indus trial mass production by enabling lean printing based solar cell processes. Proceedings 35th IEEE PVSC 2010; 28 34, DOI: 10.1109/PVSC.2010.5614042

9. Urrejola E, Peter K, Plagwitz H, Schubert G. Silicon diffusion in aluminum for rear passivated solar cells. Applied Physics Letters 2011; 98: 153508, DOI: 10.1063/1.3579541

10. Rauer M, Woehl R, Schmiga C, Hermle M, Hörteis M, Biro D. Aluminum alloying in local contact areas on dielectrically passivated rear surfaces of silicon solar cells. IEEE Electron Device Letters 2011; 32(7): 916 918, DOI: 10.1109/LED.2011.2143385

11. Krause J, Woehl R, Rauer M, Schmiga C, Wilde J, Biro D. Microstructural and electrical properties of different sized aluminum alloyed contacts and their layer system on silicon surfaces. Solar Energy Mate rials \& Solar Cells 2011; 95: 2151 2160, DOI: 10.1016/j.solmat.2011.03.017

12. Gatz S, Bothe K, Müller J, Dullweber T, Brendel $\mathrm{R}$. Analysis of local Al doped back surface fields for high efficiency screen printed solar cells. Energy Procedia 2011; 8: 318 323, DOI: 10.1016/j.egypro.2011.06.143

13. Lauermann T, Zuschlag A, Scholz S, Hahn G, Terheiden B. The influence of contact geometry and sub contact passivation on the performance of screen printed $\mathrm{Al}_{2} \mathrm{O}_{3}$ passivated solar cells. Proceedings 26th EU PVSEC 2011; 1137 1143, DOI: 10.4229/ 26thEUPVSEC2011 2DO.1.6

14. Müller J, Bothe K, Gatz S, Brendel R. Modeling the formation of local highly aluminum doped silicon 
regions by rapid thermal annealing of screen printed aluminum. Physica Status Solidi RRL 2012; 6(3): 106 113, DOI: 10.1002/pssr.201105611

15. Godlewski MP, Baraona CR, Brandhorst HW. Low high junction theory applied to solar cells. Proceedings 10th IEEE PVSC 1973; 40 48, DOI: 10.1016/0379 6787(90)90022 W

16. Huster F. Investigation of the alloying process of screen printed aluminium pastes for the BSF formation on silicon solar cells. Proceedings 20th EU PVSEC 2005; 14661469.

17. Lölgen P. Surface and Volume Recombination in Silicon Solar Cells. PhD Thesis, University of Utrecht, 1995, ISBN: 903930548 X

18. Uruena De Castro A, John J, Beaucarne G, Choulat P, Eyben P, Agostinelli G, van Kerschaver E, Poortmans J, Mertens R. Local Al alloyed contacts for next generation Si solar cells. Proceedings 24th EU PVSEC 2009; 1483 1486, DOI: 10.4229/24thEUPVSEC2009 2CV.2.22

19. Murray JL, McAlister AJ. The Al Si system. Bulletin of Alloy Phase Diagrams 1984; 5(1), DOI: 10.1007/ BF02868729

20. Yoshikawa T, Morita K. Solid solubilities and thermo dynamic properties of aluminum in solid silicon. Journal of the Electrochemical Society 2003; 150: 465 468, DOI: 10.1149/1.1588300
21. del Alamo J, Eguren J, Luque A. Operating limits of al alloyed high low junctions for BSF solar cells. Solid State Electronics 1981; 24: 415 420, DOI: 10.1016/ 0038 1101(81)90038 1

22. Urrejola E, Peter K, Plagwitz H, Schubert G. Al Si alloy formation in narrow $\mathrm{p}$ type $\mathrm{Si}$ contact areas for rear passivated solar cells. Journal of Applied Physics 2010; 107: 124516, DOI: 10.1063/1.3579541

23. Lölgen P, Sinke WC, Leguijt C, Weeber AW, Alkemade PFA. Boron doping of silicon using coalloying with aluminium. Applied Physics Letters 1994; 65: 2792 2794, DOI: 10.1063/1.112992

24. Rauer M, Schmiga C, Glatthaar M, Glunz SW. Alloying from screen printed aluminum pastes containing boron additives. IEEE Journal of Photo voltaics 2013; 3(1): 206 211, DOI: 10.1109/ JPHOTOV.2012.2217113

25. Yoshikawa T, Morita K. Thermodynamics of solid silicon equilibrated with $\mathrm{Si} \mathrm{Al} \mathrm{Cu}$ liquid alloys. Journal of Physics and Chemistry of Solids 2005; 66: 261 265, DOI: 10.1016/j.jpcs.2004.08.036

26. Sentaurus. Synopsys Inc.: Mountain View, CA, 2005.

27. Altermatt PP. Models for numerical device simulations of crystalline silicon solar cells a review. Journal of Computational Electronics 2011; 10: 314 330, DOI: 10.1007/s108250110367 6 